\title{
Assessment of Natural Resource Potential of a Territory for Planning of Investment Development and Construction in Suburban Areas
}

\author{
Marina Usoltceva ${ }^{1, *}, \quad$ Yulia Volkova $^{1}, \quad$ Artyom Radchenko ${ }^{1}, \quad$ Inna Guseva ${ }^{1}$, \\ Tatiana Makarova ${ }^{1}$, Vitaly Garmanov ${ }^{2}$, and Karl-Otto Wenkel ${ }^{3}$ \\ ${ }^{1}$ Peter the Great St. Petersburg Polytechnic University, 195251 Polytechnicheskaya str. 29, \\ St. Petersburg, Russia \\ ${ }^{2}$ St. Petersburg State Agrarian University, 196601 Peterburgskoye shosse 2, St. Petersburg, Russia \\ ${ }^{3}$ Leibniz-Centre for Agricultural Landscape Research, 15374 EberswalderStraße 84, Müncheberg, \\ Germany
}

\begin{abstract}
The paper describes the types of assessment and assessment process of the natural environment. A review of judgments about the ecological and geo-ecological assessment of the environment by known academics, environmentalists, physical geographers, geobotanists is made here. In this paper the method of the environmental assessment of natural resource potential within the North-West region of Russia is proposed. Authors divide this method into blocks, which are described in the paper. A produced method for evaluating territory used to calculate the cadastral value of land.
\end{abstract}

\section{Introduction}

Evaluation of natural bodies and phenomena is a form of reflection of the interaction between society and nature. Due to the fact that in themselves natural bodies and phenomena have neither useful nor harmfulness should clearly indicate what is the object of evaluation, and in the interests of what subject it is produced. Proceeding from the above, the assessment is the process of establishing conformity assessment facility requirements to it by the subject expressed in the form of regulatory or other assessment categories. In view of the fact that each assessment is subjective, the proximity of the two estimates, we can speak only in the event that there is similarity of the positions of subjects of evaluation.

According to the process of estimating the evaluation can be divided into direct and indirect ones. Assessments can be divided into private, comprehensive and multi-criterial by the manifestation of systemic criteria. Private assessments are separate comparison of baseline characteristics with the accepted background levels and standards. This usually exploded assessment determining a positive or negative significance of the object. Private assessments are traditional geographical and environmental studies. They form the basis of

* Corresponding author: slcvmrn@,rambler.ru 
integrated and multicriterial assessment of natural and economic systems. Integrated assessments are to establish the significance of the object on the set of indicators. Comprehensive assessment as a rule is not systemic, since the concept of "complex" and "system" is not identical to each other. This is the most perspective, but the least developed and standardized assessment. The founder of an integrated approach to the study of the natural environment is V.V. Dokuchaev. His ideas had been enhanced by L.S. Berg, A.I. Voeikov and other scientists.

Multicriterial (synthetic) assessment establish the importance of an object by constructing a vector of values of normalized parameters of the object or by the convolution of information on the state of the object as a function of desirability. These assessments are systemic; they suggest the need for a specific procedure clotting information, which is a goal-oriented process, based on clear principles of selecting or designing the most informative variables of the system - the index of its condition. These indexes can be represented by a single number (one-dimensional code), or a set of numbers (multivariate index) $[1,2]$.

Multicriterial assessment of a territory includes determining the usefulness of its properties for production non-economic and economic ways. Non-economic method is based on determining the value of the territory, is not expressed in economic terms, and economic way - by determining its social usefulness in satisfying human needs for food security through agricultural production [3, 4]. On this basis, with the multicriterial assessment territory as non-economic way we use aeco-geographical approach, and as economic way we use an inventory approach.

Results of the assessment usually expressed in the form of two basic forms: verbal and numerical. The verbal form is a qualitative characteristic of the assessment results, divided into comparative gradations, such as "suitable", "relatively suitable", "average fitness", "relatively suitable", "unfit" and the digital form is a record of verbal forms scores, grades, or categories of direct calculation indices.

\section{Eco-geographical and cadastral approaches to estimating the land resources}

The geographical assessments of environment is focused on a comprehensive study of nature, to establish the nature of the interaction between human society and the geographical environment [4].

Objects of the geographical environment assessments are natural or anthropogenic changes in geosystems of different hierarchical levels. In assessing characteristics such as geosystems: their structure, spatial and temporal variability, particularly peculiar geosystems biogeochemical cycles of chemical elements, spatial relationships between the natural and social objects within geosystems, interconnection and interoperability of geographic phenomena occurring in the ecosystems and others are determined.

Along with geosystem in geographical studies are widely used term environmental systems (TES), which refers to a space-time system of geographic components, interrelated in their placement and developing as a whole [5,6]. However, it should be noted that compared to geosystem of natural-territorial complex (NTC) has a broader interpretation, since the term NTC applicable only to certain geographical parts of the shell, but does not apply it as a whole.

Thus, the assessment of the geographical environment is focused on the analysis of its present state, identifying ways of its development, to determine the degree and direction of human impacts on nature, the study of the deep bonds of abiotic factors and determining the importance of natural ingredients for the society. The main content of this assessment is a complex physical-geographical regionalization of the earth's surface or the properties of 
geosystems different hierarchical levels, zoning largest integral indicators of the natural environment, the identification of conditions for rational use and protection of natural resources.

The objective of the environmental assessment of the environment according to Odum [7] is the answer to the question: how many organisms inhabit this area, when and where they can be found and why. At the same time, in his opinion, as the subject of the evaluation should serve biological systems superorganism level. N.F. Reimers considers environmental assessment of the environment as a process of determining the state of the environment or the life of the impact on it of any factors (taking into account also the dynamics of the impact) [4].

V.V. Dmitriev under the environmental assessment of the environment understands: 1) determination of the suitability of natural systems and their components for living organisms; 2) parametric definition of the natural environment, ensure the existence of communities living organisms characteristic of these states in terms of a natural or manmade conditions for their development; 3) obtaining based on multicriterial "portrait ecosystems" and relating it to the "standard portrait" of the same ecosystem; 4) subject object criterial assessment of a natural object from a sustainable functioning of ecological communities, save them in the natural course of successional processes or from the standpoint of the degree of suitability (potential usefulness) for his people (society) $[1,2]$. A.G. Isachenko states that any environmental assessment is biocentric, it examines only one side of the interaction in the life environment, i.e., the ties that focus on living, and relationships in the abiotic parts of the system and feedbacks directed from the living to the inanimate essentially remain outside research interests [8]. In addition, the author emphasizes the weakness of the environmental assessment of the environment, which, in his opinion, is "one size fits all" major categories of assessments, that is, uncertainty in its spatial boundaries and no territorial "bindings".

Thus, the subject of the environmental assessment of the environment is a living systems superorganism level existing in natural or modified conditions, and is focused on the assessment of management and optimal operation of these systems with the needs of society. Recently intensively developing geo-ecological, geographical and environmental assessments of the environment are used. The relationship of geography and ecology in the study of the natural environment first is stressed by Sochava [9].

Geoecology tasks in the process of its development became more sophisticated, so if at the end of the 70s in German Geoecology considered only as the doctrine of the natural landscape of the budget, which is qualitatively and quantitatively investigated through the cycling of matter, by the $80 \mathrm{~s}$ it was formed in the scientific field that studies spatial and functional aspects of social and natural systems of different ratings. The transfiguration geoecology, unlike bio-ecology, studying not only the paired connection "living system - environment", but also network-mediated relationships between the components of geographical systems included in the scope of his study mechanisms of adaptation of human society to natural and anthropogenic environmental changes [10].

Thus, geo-ecological assessment of a territory is focused on diagnosis of the natural and anthropogenically modified geosystems different hierarchical levels; on the analysis of environmental impacts, including human beings; on geosystems; to clarify the stability of geosystems to these impacts; to determine the trajectory of geosystems behavior for different types of impacts; the determination of the natural ecological potential of geosystems, etc. Consequently, geo-ecological assessment is a spatial parametric analysis capability of natural and anthropogenic changes in terrestrial systems in different types of human impacts steadily to serve life support (environment and resource reproduction).

Cadastral assessment of land has arisen as a result of the introduction of private ownership of land and payment for land use, land market development, reforming the tax 
system and collection of land rent for the land. It is applied economic analysis of supply and demand of land for a specific functional use and forecast of the likely offer price areas in the land market. This task is designed to solve the massive state cadastral valuation of lands conducted within the administrative-territorial units.

State cadastral assessment of land is based on a statistical analysis of market prices and other information about the objects of real estate, as well as on methods of mass appraisal of real estate.State cadastral assessment of agricultural land outside of urban and rural settlements and forest land is based on the capitalization of the estimated rental income, as well as other categories of land on the basis of the estimated rental income capitalization, and on the basis of costs to reproduce or preserve and maintain the value of their natural potential [11-14].

The results of state cadastral assessment of land are in the form of evaluation zoningscheme. Evaluation of the land area is recognized, uniform for the intended purpose, since the functional use and close to the value of cadastral value of land state cadastral valuation of land is carried out based on the data of the land, urban, forest, water and other inventories. The results of state cadastral valuation of land approved by the executive authorities of the Russian Federation and entered into the State Land Cadaster. Consequently, the state cadastral assessment of land is a set of legal, administrative and technical measures aimed at establishing the cadastral value of land as a certain date.

\section{Procedure of the geo-resource potential assessment in Russian North-West Region}

Based on the basic provisions of the system analysis can be formed the following procedure of the geo-resource potential assessment within the North-West region of Russia (Fig. 1).

In view of the fact that in this region consists of several major administrative entities having a certain economic independence, each of them should be regarded as an independent object of ecological and geographical land evaluation. Accordingly, the factors involved in the evaluation, for all administrative units included in the study region should be united, but their qualitative scale is individual. A briefly description of each of the blocks method used is given in the following:

The first block includes the collection and study of scientific research, literature references, statistical and cartographic materials that characterize the region under study, and especially its development.

The list of indicators is determined while realizing the second block on the base of analysis of collected materials. These indicators characterize nature-agricultural potential of the research region. Then indicators are chosen which will be participated in the assessment. After that "tree of properties" is constructed with usage of choosing models.

The third block is advisable to use expert methods of pare comparisons for determination of irregular coefficients of coefficient significance which are included in "the tree of properties".

This choice was caused by simplicity of expertize holding and good results of expert analysis.

Scientific and methodological providing of expert survey includes development of formalized questionnaires and guidance on how to fill them.

One of the most important questions, which are considered on this stage, is question of expert number determination. This is due to the fact that big number of experts can raise cost of expertise but their little number can't provide to get objective expert data of analysis. The optimal number of experts is 8-12 persons in dependence of expertise difficulty and from experience of providing. 
While realizing this method pares of alternatives are presented to experts, in which is suggested to choose more preferred consideration [15]. As a result-matrix of pare comparisons is formed. Then components of it eigenvector are determined on lines with usage of dependences. After that irregular vectors of priority are considered with usage of dependences.

$$
\begin{gathered}
\sqrt[4]{\left(W_{1} / W_{1}\right) \times\left(W_{1} / W_{2}\right) \times\left(W_{1} / W_{3}\right) \times\left(W_{1} / W_{4}\right)}=a \\
\sqrt[4]{\left(W_{2} / W_{1}\right) \times\left(W_{2} / W_{2}\right) \times\left(W_{2} / W_{3}\right) \times\left(W_{4} / W_{4}\right)}=b \\
\sqrt[4]{\left(W_{3} / W_{1}\right) \times\left(W_{3} / W_{2}\right) \times\left(W_{3} / W_{3}\right) \times\left(W_{4} / W_{4}\right)}=c \\
\sqrt[4]{\left(W_{4} / W_{1}\right) \times\left(W_{4} / W_{2}\right) \times\left(W_{4} / W_{3}\right) \times\left(W_{4} / W_{4}\right)}=d \\
S=a+b+c+d \\
P_{1}=a / S \\
P_{2}=b / S
\end{gathered}
$$

After calculation of irregular priority vectors the consistency of expert's opinions is considered by following dependences:

$$
\begin{gathered}
F_{1}=\left(W_{1} / W_{1}\right)+\left(W_{2}+W_{1}\right)+\left(W_{3} / W_{1}\right)+\left(W_{4} / W_{1}\right) \\
F_{2}=\left(W_{1} / W_{2}\right)+\left(W_{2}+W_{2}\right)+\left(W_{3} / W_{2}\right)+\left(W_{4} / W_{2}\right) \\
F_{3}=\left(W_{1} / W_{3}\right)+\left(W_{2}+W_{3}\right)+\left(W_{3} / W_{3}\right)+\left(W_{4} / W_{3}\right), \\
F_{4}=\left(W_{1} / W_{4}\right)+\left(W_{2}+W_{4}\right)+\left(W_{3} / W_{4}\right)+\left(W_{4} / W_{4}\right), \\
\lambda_{\max }=F_{1} \times P_{1}+F_{2} \times P_{2}+F_{3} \times P_{3}+F_{4} \times P_{4} \\
I C=\left(\lambda_{\max }-n\right) /(n-1) \\
R C=I C / Z
\end{gathered}
$$

Where IC is the index of the consistency of expert's opinions; OC is the relatively consistency of expert's opinions; $\mathrm{Z}$ is the random consistency; $\mathrm{n}$ is the number of compared indicators. (Figure 1) 


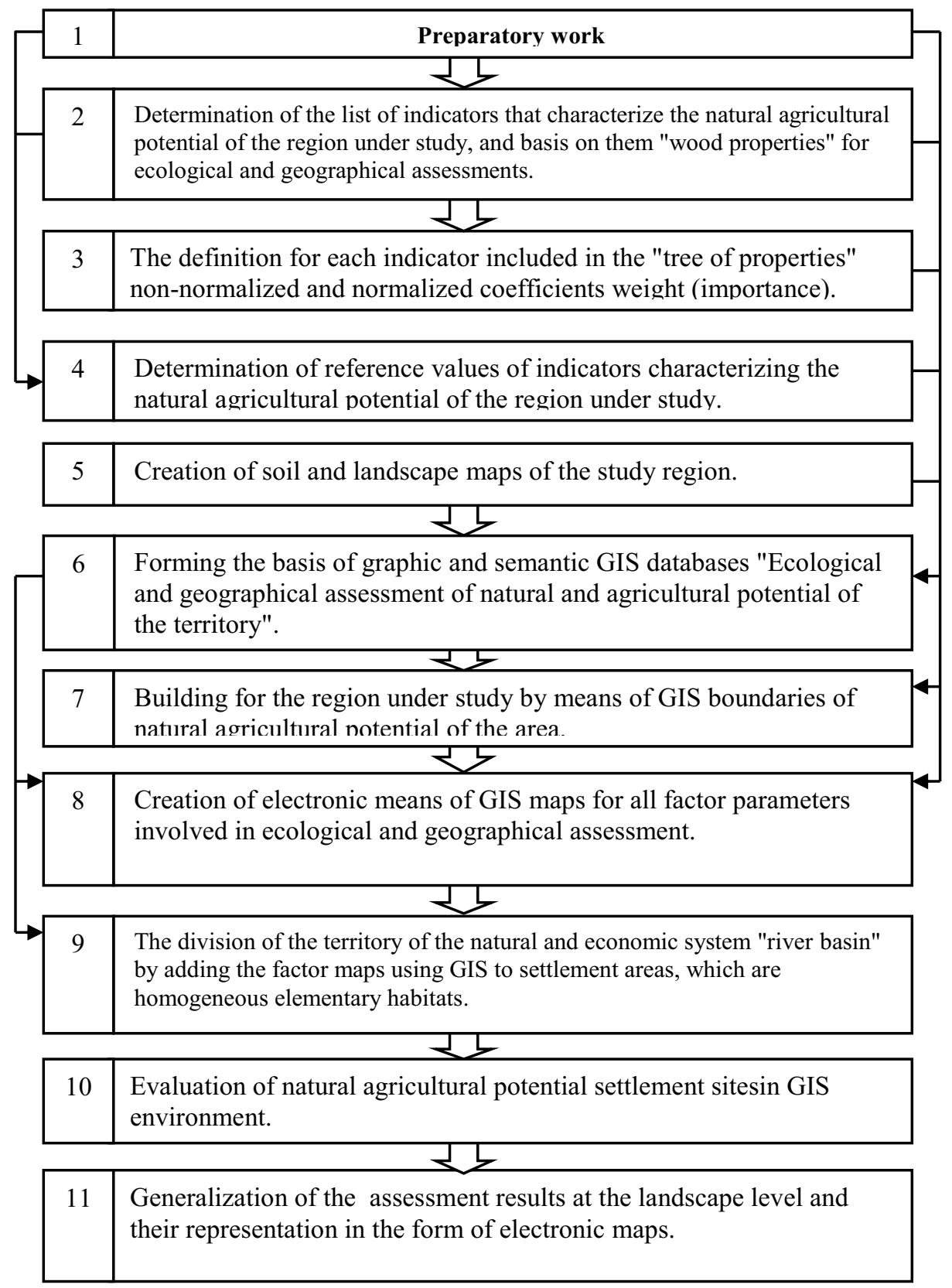

Fig. 1. Block diagram of the methodology of ecological and geographic assessments of natural and agricultural potential of the area.

The relative consistency of expert's opinions is considered acceptable if it is in the range from 0 to $10 \%$. Otherwise, the experts need to revise their judgments. The normalized coefficients of the importance of each indicator which participate in the evaluation are calculated according to the following dependence:

$$
P_{j}=\bar{P}_{j 1} \times \ldots \times \bar{P}_{j n}
$$


Where $P_{j}$ is the normalized importance of the $j$-th elementary (quasielementary) properties; $P_{j 1}, \quad \bar{P}_{j n}$ is average unstandardized coefficients of importance of the $i$-th and $n$-th level of the tree properties of hierarchically related within the same branch with the $j$-th elementary (quasielementary); $\mathrm{n}$ is the number of levels in "the tree of properties".

According to the dependences of the normalized weight (importance) elementary (quasielementary) properties, $\mathrm{P}_{\mathrm{j}}$ is calculated by multiplying the average unstandardized coefficients of importance of the individual properties $\overline{\mathrm{P}}_{\mathrm{j} 1} \ldots \mathrm{P}_{\mathrm{jn}}$ hierarchically related to each other in "the tree of properties".

The fourth block. While implementing of this unit there are defines the standardized, i.e. the best for each administrative region, values of indicators of natural and agricultural potential of landscapes. For this purpose stock, regulatory materials, data of field surveys and aerospace information are used.

The fifth block. Landscape and soil maps for research region are developed by typical methods in scale of base material [16, 17-19]. While the preparation of landscape maps objects of mapping are natural-territorial complexes in the rank of the individual tracts or typologically similar groups [20-23].Using and development of soil maps are impossible without pervasive soil researches, especially when the case is connected to the soil moisture [24-28].

The sixth block. It includes the creation of digital models of basic cartographic principles, soil and landscape maps in the research region, their entry in the created GIS and design on the adopted conditional signs. In parallel to this there is performed the semantic content of the database information which is necessary for the production of ecogeographical assessment of natural and agricultural potential [29].

The seventh block. The construction of the boundaries of the natural-economic systems called "river basin" within the limits of the studied region is carried out in a GIS environment on a digital landscape model of basic cartographic foundation and automated with the help of a special software.

The eighth block. The graphical display of spatially referenced information about the level of demonstration in limits of natural and commercial system "river basin" of researching indicator is mean as a factor map. Factor maps are prepared in GIS with usage of standard or special developed software [30].

The ninth block. There is the summation of the factor maps in the process of implementation of this unit using the "overlay" method. Ultimately, the study area is divided into design areas which are represented by homogeneous elementary areas within of which each of the analyzed indicator has only one value.

The tenth block. The assessment of natural and resource potential of designed areas is carried out in the following sequence.

1) For all elementary and quasielementary properties within "the tree of properties" the absolute values are determined. In that case, if the indicator is amenable to the methods of physical measurements, its values are expressed in any physical units, and otherwise in points.

2) For all elementary and quasielementary properties within "the tree of properties" with usage of the relations (16) and (17) the relative values of their indicators are determined as follows:

$$
\begin{aligned}
& R_{p j}=W_{p j} / W_{j \ni} \text { while } W_{p j}<W_{j \ni}, \\
& R_{p j}=W_{j s} / W_{p j} \text { while } W_{p j}>W_{j \ni}
\end{aligned}
$$


Where $R_{p j}$ is the relative value of indicator characterizing the $\mathrm{j}$-th elementary (quasielementary) property of the $\mathrm{p}^{\text {th }}$ design area, $R_{p j}$ is changed in limits from 0 till 1 $\left(0<R_{p j}<1\right) ; W_{p j}$ is the absolutevalue of indicator characterizing the $\mathrm{j}^{\text {th }}$ elementary (quasielementary) property of the $\mathrm{p}^{\text {th }}$ designarea; $W_{j e}$ is the standard absolutevalue of indicator characterizing the $\mathrm{j}^{\text {th }}$ elementary (quasielementary) property.

3) The value of the composite indicator of natural and agricultural potential design area is determined using the following relationship:

$$
K_{p}^{0}=\sum_{j=1}^{n} R_{p j} \times P_{j}
$$

where $K_{p}^{0}$ is the composite indicator describing the natural-resource potential of the $\mathrm{p}^{\text {th }}$ design area.

The high natural resource potential has the current design area in which the indicator $K_{p}^{0}$ has the greatest value. The index " 0 " in the indicator $K_{p}^{0}$ means that the assessment is given in relation to the very low (zero) level in the hierarchy of properties, i.e. in relation to the quality of natural resources. If the objects are compared, in comparison variants the best quality has the object which indicator $K_{p}^{0}$ will have the biggest difference. The ratio of quality assessments will accurately reflect the reality only in the case when the assessment is made.

The eleventh block. Natural and resource potential of the landscape is a weighted value that characterizes the potentials of design areas located within it:

$$
L_{m}^{0}=\sum_{d=1}^{n} K_{d}^{0} \times Q_{d},
$$

where $L_{m}^{0}$ is natural and resource potential of the $\mathrm{m}^{\text {th }}$ landscape; $Q_{d}$ is share in the landscape of design areas with $\mathrm{d}^{\text {th }}$ natural resource potential; $K_{d}^{0}$ is score characterizing the $\mathrm{d}^{\text {th }}$ natural resource potential of design areas.

The twelfth block of methodology is intended to represent the results of natural and agricultural $[31,32]$ potential assessment of the territory in the form of a series of electronic cards, comprising a set of factor maps and the final map describing the distribution of values of natural and agricultural potential within the study region. Agricultural potential calculation is tightly connected to the soil properties researches and experiments [20-22, 26-28].

\section{Conclusions}

On the base of conducted analysisis we can make further conclusions. The assessment of natural bodies and phenomena is a form of reflection of the interaction between society and nature. Direct assessments establish the importance of the object in the set of properties that define it. Indirect assessments establish the importance of the object on functional indicators and correlations between measured properties. The manifestations of assessment systemic can be divided into private, comprehensive, and multi-criteria assessments. Multi- 
criteria assessment of land includes the determination of the usefulness of its properties for the production of non-economic and economic ways.

There are two approaches to the assessment of land resources: ecological and geographical and cadastral. Geo-ecological assessment is parametric spatial analysis of capabilities of natural and anthropogenicallymodified geosystems at the various types of anthropogenic impacts steadily to perform life functions. State cadastral assessment of land resources is a complex of legal, administrative and technical measuresaimed at establishing the cadastral value of land as at a certain date [33].There is a method of geo-ecological assessment of natural resource potential within the North-Western region of Russia, which consists of 12 blocks. This methodology can be used to assess the natural and resource potential of the territory for the calculation of the cadastral cost of the land when planning investment development of territories [32-36].

The research was supported by DAAD (A/10/01103), DFG (MI 526/3-1) and Russian Foundation for Basic Research (\#16-04-01473-a).

\section{References}

1. V.V. Dmitriev, Diagnostics and modeling of aquatic ecosystems, Saint Petersburg: Publisher SPbSU (1995)

2. V.V. Dmitriev, Vestnik SPbSU, 14, 60-70 (1994)

3. N. Arefiev. M. Mikhalev, D. Zotov, K. Zotov, N. Vatin, O. Nikonova, O. Skvortsova, S. Pavlov, T. Chashina, T. Kuchurina, V. Terleev, V. Badenko, Y. Volkova, V. Salikov, K. Strelets, M. Petrochenko, A. Rechinsky, Procedia Engineering, 117, 3238 (2015)

4. N.F. Reymers, Natural resources: dictionary (Misl', Moscow,1990)

5. A.G. Isachenko, Izv. VGO, 6, 97-101 (1991)

6. A.G. Isachenko, Izv. VGO, 4, 45-54 (1991)

7. U.P. Odum, Fundamentals of ecology (Mir, Moscow, 1975)

8. A.G. Isachenko, Ecological geography of the North-West of Russia (Russian geographic society, Saint Petersburg, 1995)

9. V.B. Sochava, Geography and ecology (Geographical society of USSR, Novosibirsk, 1970).

10. V.S. Preobrazhensky, New conceptions in geography and forecasting, 8-21 (1993)

11. N. Arefiev, V. Garmanov, V. Bogdanov, Y. Ryabov, V. Terleev, V. Badenko, Procedia Engineering, 117, 26-31 (2015)

12. S.I. Nosov, State cadastral valuation of lands of agricultural purpose: practice manual (Publisher house "Russkaya otsenka", Moscow, 2006)

13. Resolution of the Government of the Russian Federation from 25.081999 No. 945 "On the State cadastral valuation of lands" (Moscow, 1999)

14. N.V. Arefiev, Management of natural and manmade systems: introduction to ecoinformatics (Publisher of SPbSPU, Saint Petersburg, 2000)

15. N. Arefiev, V. Terleev, V. Badenko, Procedia Engineering, 117, 39-44 (2015)

16. A.G. Isachenko, Methods of field of landscape research and landscape-ecological mapping (Publisher of SPbSU, Saint Petersburg, 1999)

17. N.S. Chochia, Summer field practice of landscape science (Publisher Leningrad State University, Saint Petersburg, 1969)

18. V.M. Chupahin, The basics of landscape learning (Agropromizdat, Moscow, 1987)

19. M.G. Ryzhakova, V.I. Maslikov, A.N. Chusov, V.V. Korablev, Applied Mechanics and Materials, 675-677, 761-769 (2014)

20. V. Badenko, V. Terleev, A. Topaj, Applied Mechanics and Materials, 635-637, 16881691 (2014) 
21. R.A. Poluektov, S.M. Fintushal, I.V. Oparina, D.V. Shatskikh, V.V. Terleev, E.T. Zakharova, Archives of Agronomy and Soil Science, 48, 609-635 (2002)

22. R.A. Poluektov, V.V. Terleev, Proceedings of the Workshop, Leibniz Centre of Agricultural Landscape Research (ZALF) in Müncheberg/Germany, 75-89 (2007)

23. R.A. Usmanov, N.I. Vatin, V.A. Murgul, Applied Mechanics and Materials, 680, 474480 (2014)

24. V. Badenko, V. Terleev, N. Arefiev, J. Volkova, O. Nikonova, Proceedings of the AASRI International Conference on Industrial Electronics and Applications (IEA 2015). Book Series: AER-Advances in Engineering Research, 2, 452-455 (2015)

25. R.A. Poluektov, V.V. Terleev, Russian Meteorology and Hydrology, 11, 70-75 (2002)

26. R.A. Poluektov, V.V. Terleev, Russian Meteorology and Hydrology, 12, 73-77 (2005)

27. V.V. Terleev, W. Mirschel, U. Schindler, K.-O. Wenkel, International Agrophysics, 24, 381-387 (2010)

28. R.A. Poluektov, I.V. Oparina, V.V. Terleev, Russian Meteorology and Hydrology, 11, 61-67 (2003)

29. A. Nikonorov, S. Pavlov, V. Terleev, N. Arefiev, V. Badenko, Y. Volkova, Procedia Engineering, 117, 258-263 (2015)

30. N. Arefiev, V. Badenko, A. Nikonorov, V. Terleev, Y. Volkova, Procedia Engineering 117, 20-25 (2015)

31. S. Medvedev, A. Topaj, V. Badenko, V. Terleev, IFIP Advances in Information and Communication Technology, 448, 252-261 (2015)

32. V.V. Terleev, A.G. Topaj, W. Mirschel, Russian Meteorology and Hydrology, 40, 278285 (2015)

33. V. Chechevichkin, N. Vatin, Applied Mechanics and Materials, 641-642, 409-415 (2014)

34. A. Makarov, A. Mihailova, N. Arefiev, S. Pavlov, T. Chashchina, V. Terleev, V. Badenko, Procedia Engineering, 117, 225-231 (2015)

35. O. Skvortsova, A. Dashkina, E. Petrovskaia, V. Terleev, A. Nikonorov, V. Badenko, Y. Volkova, S. Pavlov, MATEC Web of Conferences, 53, 7 (2016)

36. V. Terleev, E. Petrovskaia, N. Sokolova, A. Dashkina, I. Guseva, V. Badenko, Y. Volkova, O. Skvortsova, O. Nikonova, S. Pavlov, A. Nikonorov, V. Garmanov, W. Mirschel, MATEC Web of Conferences, 53, 6 (2016) 